\title{
Facile In-situ Reduction Method for Preparation of GO-Pd Catalysts
}

\author{
A. Moreno-Bárcenas ${ }^{1}$, J.F. Perez-Robles ${ }^{1}$, YV Vorobiev ${ }^{1}$, Pech-Pech I.E ${ }^{2}$, A.G. García ${ }^{3, *}$ \\ ${ }^{1}$ Centro de Investigación y de Estudios Avanzados del Instituto Politécnico Nacional. Real de \\ Juriquilla, Santiago de Querétaro, Qro. C.P. 76230, México. \\ ${ }^{2}$ Instituto Tecnológico de Cancún, Av. Kabah Km. 3., CP 77500, Cancún, Quintana Roo, México. \\ ${ }^{3}$ Laboratorio de síntesis y modificación de nanoestructuras y materiales bidimensionales. Centro de \\ Investigación en Materiales Avanzados S.C., Alianza Norte \#202, Parque PIIT, Apodaca Nuevo León. \\ C.P. 66628, México. \\ *E-mail: alejandra.garcia@ cimav.edu.mx
}

doi: $10.20964 / 2018.03 .31$

Received: 11 November 2017 / Accepted: 28 November 2017 / Published: 5 February 2018

In recent years, many researchers have developed techniques for the production of new nanostructured materials. The present work focused on the development of an environmentally friendly synthesis route with excellent catalytic properties that is; an alternative to the synthesis of nanoparticles supported on graphene oxide (GO), and it provides significant reduction in secondary waste. This method was designed for in situ reduction of highly dispersed Pd nanoparticles on the surface of GO for use in catalytic applications. X-ray diffraction measurements determined that the method yielded $\mathrm{Pd}$ mainly in the metallic state. Electrochemical characterization by cyclic voltammetry measurements showed that the increased crystallinity of Pd improved the exposure of the active electrochemical sites that carry out the oxygen reduction reaction (ORR). These results allow the design and control of the in-situ growth of nanostructured materials.

Keywords: Graphene oxide, Palladium nanoparticles, Active electrochemical sites.

\section{FULL TEXT}

(C) 2018 The Authors. Published by ESG (www.electrochemsci.org). This article is an open access article distributed under the terms and conditions of the Creative Commons Attribution license (http://creativecommons.org/licenses/by/4.0/). 